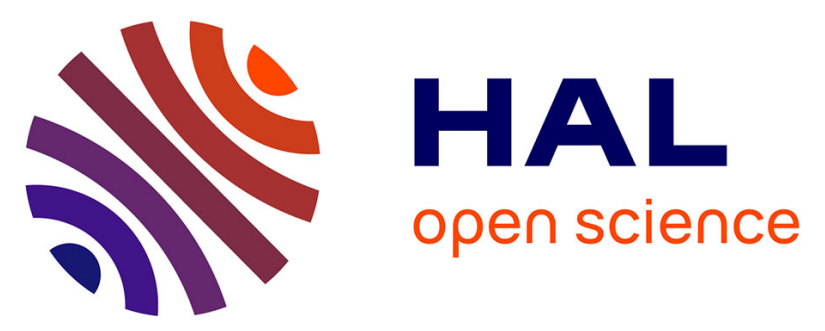

\title{
Additive manufacturing technology: the status, applications, and prospects
}

Insaf Bahnini, Mickael Rivette, Ahmed Rechia, Ali Siadat, Abdelilah Elmesbahi

\section{- To cite this version:}

Insaf Bahnini, Mickael Rivette, Ahmed Rechia, Ali Siadat, Abdelilah Elmesbahi. Additive manufacturing technology: the status, applications, and prospects. International Journal of Advanced Manufacturing Technology, 2018, 97 (1-4), pp.147-161. 10.1007/s00170-018-1932-y . hal-02309255

\section{HAL Id: hal-02309255 \\ https://hal.science/hal-02309255}

Submitted on 9 Oct 2019

HAL is a multi-disciplinary open access archive for the deposit and dissemination of scientific research documents, whether they are published or not. The documents may come from teaching and research institutions in France or abroad, or from public or private research centers.
L'archive ouverte pluridisciplinaire HAL, est destinée au dépôt et à la diffusion de documents scientifiques de niveau recherche, publiés ou non, émanant des établissements d'enseignement et de recherche français ou étrangers, des laboratoires publics ou privés. 


\title{
Additive manufacturing technology: the status, applications, and prospects
}

\author{
Insaf Bahnini ${ }^{*}$, Mickael Rivette ${ }^{2}$, Ahmed Rechia $^{1}$, Ali Siadat $^{2}$, Abdelilah Elmesbahi $^{1}$, \\ ${ }^{1}$ Research team Engineering, Innovation, and Management of Industrial Systems (EIMIS), \\ Faculty of Sciences and Technologies (FSTT), \\ Old Airport Road, KM 10, Ziaten, BP. 416 Tangier - Morocco \\ i.bahnini@uae.ac.ma ; rechia@hotmail.com ; elmesbahi_abdelilah@hotmail.com, \\ 2 Laboratoire de Conception Fabrication Commande LCFC \\ Ecole Nationale Supérieure d'Arts et Métiers \\ Augustin Fresnel Street, 57070, Metz, France \\ Mickael.RIVETTE@ensam.eu; Ali.SIADAT@ensam.eu, \\ * Corresponding author \\ ORCID iD: 0000-0001-6972-817X \\ Phone number: +212 (0) 667225267
}

\begin{abstract}
Additive manufacturing (AM) has first emerged in 1987 with the invention of stereolithography. The AM is an important, rapidly emerging, manufacturing technology that takes the information from a computer-aided design (CAD) and builds parts in a layer-by-layer style. As this technology offers many advantages such as manufacturing of complex geometries, reducing manufacturing cost and energy consumption, it has transformed manufacturing from the mass production to the mass customization. Also, it has found wide applications in several fields although some drawbacks. This paper presents the state of the art of the different AM processes, the material processing issues, and the post-processing operations. A comparison between AM and conventional processes is presented as well. We finish by presenting some prospects of this technology such as hybrid manufacturing and $4 \mathrm{D}$ printing.
\end{abstract}

Keywords: Additive manufacturing (AM), AM processes; post-processing; AM applications; 4D printing.

\section{Introduction}

The NF ISO/ASTM 52900 norm [1] has defined additive manufacturing (AM) as "the process of joining materials to make parts from 3D model data, usually layer upon layer, as opposed to subtractive manufacturing and formative manufacturing methodologies". Others terms are used to talk about additive manufacturing such as: 3D printing, layer manufacturing, freeform fabrication, etc. In addition, the designation of the process changes according to the use of produced parts. We refer to "rapid manufacturing" or "direct manufacturing" in the case of manufacturing of functional parts, "rapid tooling" in the case of additive manufacturing of tools, and "rapid prototyping", or "3D printing" for demonstration parts and prototypes [2].

\section{Classification of AM Processes}

The AM processes may be classified according to the type of energy used, the materials used, etc. We adopted the classification of Kurth [3] that has 
classified AM processes according to the material state before manufacturing. Hence, there are liquidbased, powder-based and solid-based processes. The liquid-based technologies lead to the solidification of a liquid resin in contact with a laser or with UV rays, or the fusion then the solidification of the material. Processes acting on the powder use an energy source or binding agents to form 3D parts. For solid-based processes, they use solid plates which can be bonded with a laser or with an adhesive [3]. These solid-based processes are more relevant to the removal of material and assembly processes [2]. So, we will consider only AM processes that produce complex parts, with support or not, by adding material layer-by-layer in liquid or powder state. The classification used is shown in Fig.1.

Fig.1 Classification of AM processes according to the material state before manufacturing.

\subsection{Liquid-Based Processes}

Liquid-based processes were the first AM processes to be emerged with the commercialization of stereolithography (SLA) in 1987 by 3D Systems [4]. For SLA and DLP (Digital Light Processing) technologies, the process involves the building of component (with a support as well that can be integrated according to the orientation of the part to avoid possible distortion), layer-by-layer over a vat of photo-curable resin with an energy source, which traces the $2 \mathrm{D}$ sections according to the CAD file and solidifies the resin. When a layer is completed, a leveling blade is moved across the surface to smooth it before building the next layer. The platform is lowered by a distance equal to the layer thickness, allowing the next layer to be formed. (Fig.2 Generic illustration of a SLA process - distributed under the terms of the Creative Commons Attribution, Attribution-ShareAlike 3.0 Unported (CC BY-SA 3.0) [5]). This process is similar for both SLA and DLP. The difference is the used energy-source. In SLA, a low-power, highly focused UV laser is used to solidify liquid resin, whereas the DLP use a light mask, which is dynamically created by an integrated circuit called digital micro-mirror device. The advantages of DLP technology is that it permits to harden an entire layer at once and it lets the operator choose the light intensity $(\mathrm{mW} / \mathrm{cm} 2)$ and the exposure time (s) depending on the polymerization characteristics of the resin. Generally, both SLA and DLP offer several benefits in cases where a higher feature resolution and surface quality are required [6].

The SLA technology has a newer version which is the micro-stereolithography ( $\mu \mathrm{SL}$ ) [7]. It shares the same principle with its macroscopic counterpart but in different dimensions. In the $\mu \mathrm{SL}$, a UV laser beam is focused on 1 to $2 \mu \mathrm{m}$ to solidify resin with a layer thickness of 1 to 10 microns. This resolution enables accurate manufacturing of complex 3D microstructures.

Polyjet technology was developed in 1998 in Rehovot, Israel by Objet Geometries. In 2012, it merged with Stratasys [8]. Inspired from 2D inkjet printing, Polyjet technology builds 3D objects in a layer-by-layer manner using an acrylic-based photopolymer deposited from printing heads containing many individual nozzles, which moves in the $\mathrm{x}$ and $\mathrm{y}$ axes. Each layer is cured by ultraviolet light immediately as it is printed (Fig.3 Polyjet process - Image courtesy of CustomPartNet Inc [9]). With this process, parts of multiple colors can be built.

The Fusion Deposition Modeling process (FDM) was developed by Stratasys and began to commercialize in 1991 [4]. This is a thermal process that uses a heated extrusion nozzle in order to soften or melt thermoplastic material - provided in the form of wire - onto a substrate. As the material is deposited, it cools, solidifies and bonds with the previous layers. When a whole layer is deposited, the construction platform moves down (or the nozzle move up according to the type of the machine) by an increment equal to the defined layer height, and the next layer is deposited. FDM prototypes can be viewed as composites structures composed of partially bonded filaments [10].

The FDM system head usually includes two nozzles, one for the part material and one for the support material (Fig.4 FDM process schematic distributed under the terms of the Creative Commons Attribution 4.0 International License [11]). It could include more than two nozzles which give the opportunity to build multi-colors parts.

This process has the advantage of using a wide range of materials (polycarbonate (PC), acrylonitrile butadiene styrene (ABS), polyphenylsulfone (PPSF), PC-ABS blends, and PC-ISO, which is a medical grade $\mathrm{PC}[12])$. The strengths of FDM process are 
its capability to fabricate functional parts, easiness and safety of use in an office-friendly environment, non-need supervision, and its reproducibility. For all this advantages, this process is nowadays widely used by hobbyists as well as by professionals, and found diversified applications.

\subsection{Powder-Based Processes}

Powder-based processes include a number of processes that share the same operating principle: building 3D parts from fine powder according to a CAD file. Powder-based processes can be divided into three broad categories: powder bed fusion (PBF), powder feed deposition (PFD) and powder binding.

- Powder Bed Fusion Processes

Fig.5 is a schematic of a generic powder bed system (Fig.5 A schematic of powder bed fusion system [13]). A thin layer of powder is spread by a leveling roller on the platform where a moving energy source sinter or melt the powder into successive cross-sections according to the CAD file. The platform goes down a pitch equal to the layer thickness, and the leveling roller spread another layer of powder over the solidified layer, to build the next one. This process is repeated to create a $3 \mathrm{D}$ solid component. Post-processing is necessary to remove any excess material and smooth visible surfaces. Special support structures are not required in powder-bed systems because the excess powder in each layer acts as a support to the part being built. SLS (Selective Laser Sintering), SLM (Selective Laser Melting), DMLS (Direct Metal Laser Sintering), and EBM (Electron Bean Melting) are examples of this type of processes.

The SLS process has been commercialized in 1992 by DTM which became a part of 3D Systems from 2001 [4]. This technology offers a great variety of materials that could be used: plastics, metals, combination of metals, combinations of metals and polymers, and combinations of metals and ceramics [12].

Sintering operation in SLS process leads to the construct of porous structures. This porosity can be controlled, which constitute an interest for the creation of porous membranes [14].

Concerning the SLM, it was invented by a group of researchers at the Fraunhofer ILT (Fraunhofer
Institute for Laser Technology) in Germany [15]. The SLM is a process similar to SLS. They differ in some technical details especially in the power of laser beam.

For Direct Metal Laser Sintering (DMLS), it is another commercial name used for the description of a laser-based additive manufacturing process, similar to SLS/SLM. However, the DMLS processes metallic powder only. Developed by EOS Gmbh in cooperation with Rapid Product Innovation (RPI), DMLS was first used to be a Rapid Tooling (RT) method for injection molding tools. Some of the most commonly used metals include cobalt chromium, titanium alloys, steel alloys and tool steels [16].

Another powder bed fusion process is the EBM. The EBM machines were first commercialized, around 1997, by Arcam AB Corporation in Sweden [17]. Similar to electron beam welding, the EBM uses an electron laser beam powered by a high voltage, typically 30 to $60 \mathrm{KV}$ [12], to melt fine metal powder, on the order of $10-100 \mu \mathrm{m}$, to achieve a typical layer thickness of $0.05-0.2 \mathrm{~mm}$ [17].

The process takes place in a high vacuum chamber to avoid oxidation issues. After finishing the construction, the built part is allowed to cool inside the process chamber, which is then filled up with helium as to assist cooling [17].

\section{- Powder Feed Fusion Processes}

A generic illustration of AM powder feed systems is shown in Fig.6 (Fig.6 A schematic of Powder feed fusion system [13]). Unlike powder bed processes discussed in the previous section, powder-feed systems convey the powder by a gas through a nozzle onto the build surface to inject it into the laser and deposit it in molten form into the desired shape.

The build volumes of these systems are generally larger (e.g., $>1.2 \mathrm{~m}^{3}$ for the LENS $850-\mathrm{R}$ ). Although the general approach is the same, differences between these machines commonly include changes in laser power, laser spot size, laser type, powder delivery method, inert gas delivery method, feedback control scheme, and/or the type of motion control utilized [18]. There are several processes operate similarly, but the denomination differs as each developer/company choose a different name to distinguish from others and for marketing reasons. The Laser Engineered Net Shaping (LENS) is an 
example of these processes. This technology was commercialized by Optomec in 1998, based on technology developed at Sandia National Labs [4].

The method uses an Nd: YAG laser $(\lambda=1.06 \mu \mathrm{m})$ and a higher power 300w [19] to melt metal powder conveyed by an inert carrier gas (to prevent oxidation) put on pressure in a deposition nozzle fixed relatively to the laser. The set (laser - nozzle) is called projection head. In this way the parts are made by moving the projection head.

\section{- Binding Processes}

The three dimensional printing process (3DP) was patented in 1994. It was developed at the Massachusetts Institute of Technology (MIT) and licensed to several corporations [20]. The process is similar to the SLS process, but instead of using a laser to sinter the material, an inkjet printing head deposits a liquid adhesive that binds the powder particles and form 3D components.

3DP offers the advantage of fast build speeds. However, the accuracy, surface finish, and part strength are not quite as good as some other additive processes [21]. For this reason, this process is typically used for the rapid prototyping of conceptual models.

\section{Post-processing}

After finishing the fabrication with an AM process, parts are not ready for most end-use applications. A post-processing operation is then required to prepare parts for their intended use. The reasons for post-processing are various: remove the excess powder and the support structure, improve the mechanical proprieties and enhance the surface quality. Here we present most employed postprocessing for additively manufactured parts.

\subsection{Support Removal}

Support removal is the most common type of post-processing in AM. Support material can be broadly classified into two categories: (i) material which surrounds the part as a naturally-occurring byproduct of the build process (natural supports), and (ii) rigid structures which are designed and built to support, restrain or attach the part being built to a build platform (synthetic supports) [22].

Processes which provide natural supports are specifically powder bed fusion (PBF) and binder printing processes, which require removal of the part from the loose powder surrounding the part.

In PBF processes, after manufacturing, the part should remain embedded inside the powder to minimize part distortion and allow it to go through a cool-down stage. Then, the loose powder can be removed by brushes or compressed air. Internal cavities and hollow spaces can be difficult to clean and may require significant post-processing time.

For binder printing processes, infiltration is necessary to strengthen the part. The same thing is applied to PBF materials that require postinfiltration, such as some elastomeric materials, polystyrene materials for investment casting, and metal and ceramic green parts [22].

\subsection{Bead Blasting and Sanding}

The removal of supports could leave witness marks on the surface where the supports were attached. Hence, these surfaces require a posttreatment with bead blasting or sanding. Bead blasting consists of applying fine beads at a high pressure without damaging the surface. For sanding, it is can be accomplished by hand or by machine. Comparing this two post-processing, Bead blasting is an inexpensive and quick solution: while sanding a part can take hours, bead blasting takes only a few minutes. This simple process also preserves a part's quality since it will not distort it or change its dimensional accuracy [23].

\subsection{Thermal Post-Processing}

After being manufactured with the AM, some parts are thermally processed to enhance their properties. Thermal post-processing is used mostly for metallic parts made by PBF and PFD to form the desired microstructures, relieve residual stresses, close pores and/or improve the mechanical performance of the material. Traditional heat treatment developed for the specific metal alloy or special heat treatment methods developed specifically for AM parts can be employed. Materials may be treated by the Hot-Isostatic Pressing (HIP) which is used to close internal pores and cracks in metal AM parts, or by furnace heating to effect changes in microstructure Thermal postprocessing of metal affects grains through recovery, 
recrystallization, and growth. Microstructure evolution is modified by dissolution, precipitation, and growth [24].

\subsection{Surface Finishing}

AM processes generate some surface-texture features on parts that need to be modified for performance reasons or for aesthetic. Common surface textures are: stair-steps; powder adhesion; fill patterns from extrusion or beam-based systems; and witness marks from support material removal [22].

Stair-stepping or staircase effect is a fundamental issue in deposition processes such as FDM, and it's difficult to overcome unless using a thin layer thickness which increases significantly the built time. Powder adhesion is also a known issue in binding, powder-bed and powder-feed processes. The type of post-processing to use depends on the part material and the desired surface finish outcome.

For metallic parts, machining, shot-peening and grinding have been widely used to achieve a greater accuracy and surface quality. To give context to surface quality expectations, aerospace applications have reportedly specified surface roughness $0.8 \mu \mathrm{m}$ $<\mathrm{Ra}<1.6 \mu \mathrm{m}$ [27]. Chemical processes are also used such as electro-polishing. It was used for DMLS parts manufactured with stainless steel and cobalt chrome alloys to clean the surface from impurities, such as oils, embedded scale, and debris, and improves corrosion resistance [28].

\subsection{Post-curing}

For parts additively manufactured by photopolymer materials, a common post-processing operation for is post-curing. During fabrication, the polymerization is not achieved completely. Therefore, these parts are put into a device that floods the part with UV and visible radiation in order to completely cure the surface and subsurface regions of the part [22].. In addition, the part can undergo a thermal cure in a low temperature oven to cure the photopolymer completely, and enhance the part's mechanical properties.

\section{Material Processing Issues}

During manufacturing with an AM process, some material processing issues may occur, which affect the produced part quality. These issues are common between all AM platforms. The difference is in the influencing parameters (process parameters, machine configuration, etc.), and the interaction between them and used materials. Here we present some of the known material processing issues, i.e. porosity, residual stresses, and mechanical properties.

\subsection{Porosity}

Porosity is a defect that occurs in almost all parts manufactured by AM especially metallic AM processes. Porosity can be powder-induced, process-induced or an artefact of solidification [24]. (Fig.7 Light optical microscopy showing process induced porosity vs. gas induced porosity transferred from the powder feedstock [25]). Powder-induced porosity is a result of certain production techniques like gas-atomization (GA), plasma rotating electrode process (PREP), plasma atomization (PA)...etc. During production, powder entraps inert gas which is transferred to the part due to rapid solidification. Higher quality powders produced via the PREP do not contain such pores and have been used to eliminate powder-induced porosity in DMD [24]. The dominant reason for the formation of porosity is processing technique; hence, process parameters must be correctly set to avoid mechanisms that can create pores.

According to each process, several parameters influence the porosity of the manufactured parts, among others: laser power, scan speed, sintering orientation, grain size and the layer thickness. For DMLS, powder particle size and layer thickness have an interrelation that affects the porosity of final part. Fig.8 and Fig.9 show the difference in porosity between a $50 \mu \mathrm{m}$ and a $20 \mu \mathrm{m}$ powder grain size (Fig.8 DMLS Direct-Metal 50V-2 grain size $50 \mu \mathrm{m}$, porosity 10-15\%, (a) before and (b) after shot peening, cross section [26]) (Fig.9 DMLS DirectSteel 20V-2 grain size $20 \mu \mathrm{m}$, porosity $\sim 5 \%$, left before and right after shot-penning, cross section[26]). In fact, the small particles have better compaction and lower tendency for porosity which explains the higher density, unlike large particles. As can be seen from the Fig.8 and Fig.9, the postprocessing operation by the shot-peening enhances the surface quality and improves the density of the 
top layer of the part [29].

Sintering orientation is another factor that influences the porosity. For the SLS process, microstructure resulting from different sintering orientations has been evaluated by [30]. Obtained results show that the vertical orientation generates higher porosity that results in poor fatigue properties. After applying a HIP treatment with a temperature $1200^{\circ} \mathrm{C}$, the total densification of the material is obtained and the influence of the sintering direction in porosity and mechanical properties disappears completely [30].

For the SLM process, the laser power and the scan speed have the most significant effect on the mechanical properties and the microstructure of the produced part. Different combinations of these two parameters result in a fully consistent surface, a porous structure, or the balling defect of both kinds. (Fig.10 SEM images showing surface morphologies of SLM samples at different laser power $\mathrm{P}$ and scan speed v : (a) $\mathrm{P}=300 \mathrm{~W}, \mathrm{v}=0.05 \mathrm{~m} / \mathrm{s}$; (b) $\mathrm{P}=300$ $\mathrm{W}, \mathrm{v}=0.08 \mathrm{~m} / \mathrm{s}$; (c) $\mathrm{P}=250 \mathrm{~W}, \mathrm{v}=0.05 \mathrm{~m} / \mathrm{s}$ [31]).

For the FDM technology, the porosity is controllable and it is related to the process parameters. This is what a study [32] on the fabrication of polycaprolactone (PCL) scaffolds with honeycomb-like pattern reveals. The same conclusion was made by another study [33] which examined the effect of process parameters on the ABS scaffold structures. The DOE approach used has determined air gap and raster width as the most significant parameters affecting the porosity.

\subsection{Residual Stresses}

Residual stresses are those stresses that would exist in a body if all external loads were removed. When a material is heated uniformly, it expands uniformly and no thermal stress is produced. But when the material is heated unevenly, thermal stress is produced [34]. Residual stresses are a very common problem is additively manufactured parts, especially in metallic parts. They can negatively impact the mechanical properties, lead to geometrical distortions, act as a driving force for changes in grain structure, or in the worst case, cause cracking.

In EBM process, large temperature gradients may emerge due to selective heating of powder areas. Therefore, residual stresses may be induced and caused delamination if they exceed the bonding abilities between layers. This phenomenon depends on the scanning strategy and specifically on the orientation of the scan vectors [17].

There is a variety of techniques used to measure residual stresses such as micro-hardness, the contour method, X-ray diffraction, neutron diffraction, etc [24].

The magnitude of residual stresses and the ways to reduce them are depending on the process and the material used. For example, ceramics parts produced with SLM or EBM are much more challenging due to the high melting temperatures of ceramics such as $\mathrm{Al} 2 \mathrm{O} 3\left(>2000^{\circ} \mathrm{C}\right)$ and $\mathrm{SiO} 2\left(>1700^{\circ} \mathrm{C}\right)$, which cause high residual stresses associated with melting/re-solidifying in these laser-based AM processes [35]. To overcome this problem and reduce residual stresses, researchers recommend preheating the ceramic powder bed before the manufacturing. This helps in obtaining a nearly fully dense, crack-free part without any postprocessing [36].

Residual stresses are not only related to the high temperature, but also to some other process parameters. A study conducted by Sood et al. [37] on components manufactured by FDM process, with five input variables, namely layer thickness, orientation, raster angle, raster width and air gap concluded that the increase in the number of layers increases the number of heating and cooling cycles, which results in the accumulation of residual stresses. They reported also that raster angles affect the residual stresses. In fact, small raster angles result in long rasters that increase the accumulation of stress along the deposition direction, resulting in a weak bonding of layers and, hence, parts deformation.

According to the case, we can induce compressive residual stresses in the surface layers to improve fatigue resistance, using shot-penning. The study made by [38] for DMLS components treated by the shot-penning reveal that the repeated impacts induce compressive residual stresses that delay crack initiation and retard early crack propagation.

\subsection{Mechanical Proprieties}

Additive Manufacturing technology allows manufacturing of complex geometry parts from different feedstocks. This give engineers the opportunity to emphasize on design and functional 
optimization, rather than machinability of parts. Next to that, ensuring that AM parts have mechanical properties similar to those manufactured by conventional processes is a persistent need. For $\mathrm{AM}$, mechanical proprieties depend particularly on part orientation in space of the building. Because of the layer-by-layer manufacturing, AM parts have anisotropic proprieties.

In addition, mechanical proprieties (static and dynamic) depend on several parameters related to the process itself, the used material (feedstock quality, material color, density, method of powder compaction...), the machine (calibration, nozzle diameter for deposition processes, laser powder for laser-based processes, envelope temperature, scan/deposition strategy...), and the environment (temperature, humidity...). Other problems related to material processing should be taken into account when discussing mechanical proprieties, such as porosity, residual stress, and thermal history.

\section{Applications of AM}

Additive manufacturing has made their way into many industries and has found diversified applications in aerospace, automotive, dental and medical industries, toys, fashion and accessories, art, architecture, etc. In this section, we are going to present some of these applications.

\subsection{Aerospace Applications}

When it comes to the manufacturing of aerospace components, achieving target material properties is absolutely vital. Aerospace components often have complex geometries and a high buy-to-fly ratio (the ratio of raw material weight to the of the final part weight). They are made usually from advanced materials, such as titanium alloys, nickel superalloys, special steels or ultrahigh-temperature ceramics, which are difficult, costly and timeconsuming to manufacture [35]. Therefore, AM is highly suitable for aerospace components manufacturing.

For Arcam, it has made significant strides in this domain. With the Q20plus printer, aerospace components such as turbine blades, aerospace engines, industrial gas turbine, structural airframe components and others are produced with costefficiency and high accuracy. For these reasons, some of the leading manufacturers of aerospace components like LAI International and Alcoa have chosen the Arcam Q20plus printer [39], [40].

Optomec also has gone into action in the field of aerospace. Since 2011, it started to 3D print electronics for military aerospace applications. With Aerosol Jet printer [41], printing electronics directly onto 3D surfaces, like cell phone case or an aircraft wing is now possible. It is can print conformal sensors, antennas, shielding and other active and passive components using common electronic materials including conductor, dielectric, resistor, and semiconductor inks. This innovation has the advantage of eliminating the need for separate printed circuit boards, cabling and wiring, thereby reducing weight and size while also simplifying the assembly process.

The utilization of AM in the aerospace industry is not limited to fabricate new components, but it is extended to repair aircraft engine parts, reducing thereby the cost and extending their lifetime. Technologies used in repairing are specifically LENS and DMD. A blisk repaired by LENS is shown in Fig.11. (Fig.11 Damaged blisk repaired using LENS - [42])

\subsection{Automotive Applications}

AM technologies have found their applications in automotive industry too. It has opened doors for newer designs; cleaner, lighter, and safer products; shorter lead times; and lower costs [43]. A big challenge for manufacturing automotive parts using AM technologies is the limited build volume of current 3D printers, which restrict the production of larger components such as body panels, but significant researches are in progress to overcome this problem. On example is the mammoth stereolithography machine developed by Materialise, which has a build envelope of 2,100 mm x $680 \mathrm{~mm}$ x $800 \mathrm{~mm}$, big enough to manufacture most of the large components of an automobile. This 3D printer was used to build the outer shell of the race car "Areion," developed by Formula Group T, in just three weeks [44].

In automotive industry, tooling plays an important role on assembly line. Therefore, customizing fabrication of tooling is necessary to enhance productivity. Is this sense, BMW has used AM to make the hand tools used in testing and assembly. 
These custom-designed hand tools have better ergonomic design and are $72 \%$ lighter than traditional hand tools. The use of AM technology instead of traditional CNC machining helped reducing the lead time by $92 \%$ and costs by $58 \%$ and project time [45].

\subsection{Medical Applications}

Over the 20 last years, a great advancement in medical technologies has been made with the introduction of $3 \mathrm{D}$ printing techniques. Medical devices, orthodontic and orthopedic implants, prosthetics, bionics, medical training models and other medical equipment are now manufacturing using AM techniques. Combining medical imaging and 3D printing allows for the customization of prosthetics and implants and permits the visualization of complicated pathologies. [46].

For the MRI machines (Magnetic Resonance Imaging), Stratasys has started to produce plastic special coils - a subassembly that provides the interface with the human body part whose image is to be captured - using the FDM technology. These plastic components that have complex geometries and should meet drastic requirements have been fabricated with conventional processes such as CNC machining and injection molding with a high manufacturing cost and time. Using the FDM technology has significantly reduced machining costs (up to $78 \%$ ), manufacturing time (up to $94 \%$ ) and material waste, resulting in significant saving [47].

The AM is used also in removable orthodontic treatment. X-ray images and photographs of patient's teeth can be used for treatment plans and printing orthodontics braces to align teeth [46]. Also for orthopedic implants, Arcam has designed specifically the Arcam Q10plus [48]. With a build area that allow optimal stacking of the most common implant types, it's particularly ideal for the production of high volume press-fit implants with advanced trabecular structures as well as one-off custom implants built with data derived from computed tomography (CT) scans of individual patients.

Furthermore, 3D printing is used in manufacturing of realistic and clinically relevant anatomical models. Stratasys, with its technology Polyjet, produce multi-color models that are used for clinical training [49], and also for complex surgeries planning like separating twins conjoined. With 3D scanning and $3 \mathrm{D}$ printing, surgeons are able to produce $3 \mathrm{D}$ models to help them visualize the body part where the surgery will take place and plan every cut with meticulous detail.

Another application of 3D printing that will revolutionize the medical world is the $3 \mathrm{D}$ bioprinting, or the creation of cell tissue. The tissue engineering was facing the challenge of producing 3D vascularized cellular constructs, but with the invention of "integrated tissue-organ printer" (ITOP), printing living tissue structures such as bones and organs is now possible [50] (Fig.12 3D bioprinted ear cartilage [50]). The scientists have so far printed ear, bone, and muscle structures, conducting successful tests on animals.

\section{The AM vs Other Manufacturing Processes}

In this section, a comparison between the AM and conventional processes such as forming, plastic deformation, and CNC machining will take place.

\subsection{AM vs Forming Processes}

We are going to consider here only the sintering and molding processes. The molding is a process which, by cooling a molten material in a mold, allows the production of a solid part in the given geometry. The materials used can be metallic or polymeric. The sintering process is similar to the molding with the difference that the material used is a powder that the size and density of the grains are known. This powder is heated so that the grains fuse together, but without melting of the material. We obtain a porous component whose geometry is that of the mold.

These processes are much closer to the AM regarding the volume generation, in particular by sintering of the material for powder bed manufacturing, or polymers fusion for the material deposition. Moreover, these two kinds of processes have a common point, which is the consummation of the material amount required for the part production, (in the ideal case). However, the high price of molds and the need for a production chain heavy established make the forming processes a competitive choice comparing to the AM only in the 
case of large series production.

\subsection{AM vs Deformation Processes}

Deformation processes plastically deform materials provided in an initial simple shape and transform them to the desired final geometry with required properties. Deformation processes can be conveniently classified into bulk-forming processes (e.g., rolling, extrusion, and forging) and sheetforming processes (e.g., stretching, flanging, drawing, and contouring) [51].

The comparison between these processes and the AM can be made according to two aspects: final part properties and geometric complexity. Deformation processes guarantee an extremely metallurgical integrity of parts and allow manufacturing of moderately complex geometries with high production rate. While for the AM processes, they allow the production of complex parts with an anisotropic structure in relatively long production time.

\subsection{AM vs Machining Processes}

Is this section we discuss the differences between CNC machining and AM according to several criteria: used materials, construction speed, Geometric complexity, dimensional accuracy, and programming [52].

- Material

AM technology was developed firstly for polymeric materials manufacturing. Subsequently, composites, metals, and ceramics were introduced. CNC machining can be used for soft materials, like medium-density fiberboard (MDF), machinable foams, machinable waxes, and even some polymers. However, use of CNC to shape softer materials is focused on preparing these parts for use in a multistage process like casting [52]. For metallic end-use parts, CNC machining is more suitable as it delivers high accuracy parts with well-defined properties. In contrast, additively manufactured metallic parts may encounter some problems as discussed above in paragraph 4 . Regarding the parts structure, the CNC parts are more homogeneous while the AM parts have an anisotropic structure and may have the problem of porosity.
- Construction Speed

CNC machining is much faster than the AM machines. However, AM technology has the advantage of producing parts in a single stage, while CNC machines require considerable process planning, especially for complex geometries parts, which makes CNC machining a multistage manufacturing process, requiring the repositioning, the relocation of parts or the use of more than one machine. For AM machines, they present the advantages of manufacturing multiple parts at once, especially using powder bed processes.

\section{- Geometric Complexity}

The main advantage that AM technology has over CNC machining is the ability to manufacture complex shapes. On the contrary, CNC machining limits the design freedom and needs various equipment and tools. Moreover, it presents a possibility of collisions and difficulties to the tool to reach deeper and invisible areas during production. (Fig.13 Features that represent problems using CNC machining [52])

\section{- Accuracy}

The dimensional accuracy can be defined as the deviation between the nominal and the manufactured part dimensions. The accuracy of CNC machines is defined by the positioning resolution along the three orthogonal axes, by the diameter of the rotary cutting tools, and by some other factors related to the tool geometry. [52].

For AM, it generally operates with a resolution of a few tens of microns. The resolution is variable along different orthogonal axes. In fact, z-axis has the lower resolution, as dimensions measured along this axis are approximated by the layer thickness.

The accuracy of AM processes is quite difficult to define, as it affected by the positioning of the build mechanism (the nozzle in the case of FDM and Polyjet, and the laser in the case of SLS, SLM, etc), by the movement of the construction platform, and by the parameters of the process itself.

For CNC machining, general and specific dimensional tolerances are based on ISO standards, which ensure the production of high-quality end-use parts. However, required realistic geometrical tolerance values and standards are currently not known for the AM technologies. Some attempts to establish dimensional accuracy standards were made 
for some processes such as FDM [53] and SLM [54]. These attempts remain limited, as the determined tolerances are not generic and are related to the type of the machine and the used process.

- Programming

Determining the program sequence for a $\mathrm{CNC}$ machine involve several parameters: tool selection, machine speed settings, approach position, and angle, etc. A programming error may result in a nonproperly built part and, in the worst case, may cause severe damages to the machine and may even be a safety risk. [52]

For the programming of AM machines, there are successive steps: the creation of the geometric model, the tessellation or the conversion of CAD file to the STL file, the slicing, and generation of the construction mechanism path.

The most common method for the creation of geometric models in the industrial sector is the Computer-Aided Design (CAD). At this stage, and to take advantage of AM ability to manufacture complex shapes, a topology optimization could be applied. Next step is the conversion of the CAD file to the STL format, which is a standard exchange format for slicing software. The term STL was derived from stereolithography, or it's may also refer to Standard Tessellation Language or Standard Triangle Language. This format has some major limitations, e.g. the tessellation setting is the same on the whole part without taking into account complex areas, the loss of certain information such as specifications, mechanical properties, and information of the applied material while converting the CAD file to the STL, etc. Thus, many other formats have been proposed to replace it [55], but it is still used for its advantages such as the easiness of the implementation of slicing algorithm, the best ability of orientation of model, and the simplicity of the addition of support structure [56].

Another format, relatively new, derived from the STL is the color STL format. This format is used for models with colored surfaces such assembly inspections, building models, and jewelry models [57].

After STL exportation, slicing step is next. Slicing can be seen as the intersection of the part by a set of horizontal planes, which results in closed curves corresponding to the layers to be deposited.
The Last step is the generation of the laser scanning path or the deposition path (according to the process used). Then, a file compatible with the used machine is exported.

The numeric chain of AM processes constituted by the mentioned above steps has a lot of limitations, which are well investigated by [55]. Some solutions are also provided.

\section{New Developments and Prospects}

\subsection{Hybrid Manufacturing}

The hybrid manufacturing was first invented to overcome problems encountered specially with metal AM. The use of metallic additively manufactured components in tight tolerance and critical applications is limited by several factors, such as: part resolution, unsatisfactory surface quality, poor uniformity in material properties and mechanical properties e.g. residual stresses [27]. Therefore, it's necessary to carry out a postprocessing to achieve the required specifications, which increase significantly the cost-to-build-rate ratio and the lead time.

A possible solution to overcome these issues is to combine or to 'hybridize' two or more processes in only one machine named "Workstations for Hybrid Additive and Subtractive Processing" (WHASPS) [27]. These machines that are emerging in the market combine an additive manufacturing process with a subtractive process, such as turning and milling.

The main advantage of WHASPS is the ability to both add and subtract material, which helps to produce most complex geometries such as the internal and the overhanging features, parts with a high 'buy-to-fly' ratio like aerospace components and also to remanufacture high-value components. From an environmental point of view, these machines help to reduce material wastage and excessive consumption of tooling.

\subsection{D Printing}

It is has been nearly three decades since the first AM system was commercially available in the late 1980s. As we present earlier in this article, there is such variety of systems which differ according to the material used and the intended application. 
Besides that, a new trend at the other far end of the technology spectrum is emerging. This is time as the fourth dimension, which is combined with $3 \mathrm{D}$ printing to be known as "4D printing" [58]. The idea of including time is not about how much a part would take to be print, but it is rather the fact that objects can change their shapes over time to perform programmed functions, based simply on material properties.

The invention of 4D printing was the result of a research collaboration between Stratasys Education and R\&D departments and Massachusetts Institute of Technology's Self-Assembly Lab [59].

The technology of "4D printing" is typically based on the AM of parts using smart materials, so they can be programmed to reshape, or have embedded properties or functionality that transform them when subjected to external stimuli, supporting the notion of self-assemblies [58].

(Fig.14 Early prototype of a self-deploying truss, On heating, the length increases from $6.4 \mathrm{~cm}$ to 72.4 $\mathrm{cm}$ in $1 \mathrm{~min}$ [60]).

This notion of self-assembly is defined as "a process by which disordered parts build an ordered structure through only local interaction. In selfassembling systems, individual parts move towards a final state, whereas in self-organizing systems, components move between multiple states, oscillate and may never come to rest in a final configuration" [61]. This notion has been used at nanoscale for years, and it's used also in Active origami, where an object self-folds or self-unfolds, which help reducing the infrastructure investment for folding automations [62].

Materials that can be used in 4D printing are generally Shape-memory materials (SMMs). These materials have the unique property of "remembering" their original shape to which they return when subjected to a stimulus. SMMs include shape-memory alloys (SMAs), ferromagnetic SMAs (FSMAs) and shape-memory polymers (SMPs) [63].

4D printing is a relatively new research area. Although that it still encountered challenges at the level of technology, materials, and design [64], this technique represents the future of manufacturing since it offers a direct path from the idea to the practicality.

\section{Conclusion}

The additive manufacturing, known widely as
"3D printing", is a process of making parts from 3D model data in a layer-by-layer way. Various additive manufacturing processes, techniques, and systems are commercially available, and their numbers continue to grow.

In this review, we have broadly classified the AM processes into two categories: the liquid-based and the powder-based processes. We have presented some post-processing operations, as well as the encountered problems in material processing. In addition, some applications of the AM in different fields have been presented to show how AM technology is widely used nowadays.

After that, we have investigated the differences between the AM technology and some of the mostused processes, i.e. forming processes, plastic deformation processes, and $\mathrm{CNC}$ machining. We have dedicated the last section of our review to highlight some of the new developments in this technology. We have present the hybrid manufacturing, which is a technique that integers an $\mathrm{AM}$ and a $\mathrm{CNC}$ machining process in one machine, and the 4D printing, the new bold technology that allows the manufacturing of parts capable of changing their shapes over the time when they are subjected to an external stimulus.

Despite all this development, some issues still remain and need further research, such as the geometric specifications and the associated tolerances. As it's known for the CNC machining and some others traditional processes, the manufacturing constraints have resulted in the expression of design rules that allow the design of manufacturable parts. Tolerances and related geometric specifications are widely studied, and the standards and the design methodologies are well established.

But regarding AM processes, there are still no standards describing associated tolerances, geometrical specifications, acceptable defects, types of quality controls, etc. Moreover, there are not generic Design Methodologies for AM (DFAM) except some that have been established for some specific processes.

Thus, our work in the research team in EIMIS laboratory at FST of Tangier in partnership with LCFC laboratory at ENSAM Metz consists on the development of a methodology for the integration of tolerances and interactions between product characteristics and AM processes parameters in the 
design stage. At present, we conduct research on the FDM process, for the purpose of generalizing, in future works, the obtained results for the other AM processes.

\section{References}

[1] ASTM 52900:2015 Additive manufacturing - General principles - Terminology. https://www.iso.org/obp/ui\#iso:std:isoastm:52900:ed-1:v1:en.

[2] Boyard, N.: Méthodologie de conception pour la réalisation de pièces en Fabrication Additive. L'École Nationale Supérieure d'Arts et Métiers, 2015.

[3] Kruth, J.: Material Incress Manufacturing by Rapid Prototyping Techniques. CIRP Ann., vol. 40, no. 2, pp. 603-614, Jan. 1991.

[4] Wohlers T. Wohlers Report 2017 - Additive Manufacturing and 3D Printing State of the industry. Wohlers Associates, Inc, 2017.

[5] https://commons.wikimedia.org/wiki/File:S tereolithography_apparatus_vector.svg

[6] Mitteramskogler, G., Gmeiner, R., Felzmann, R., et al : Light curing strategies for lithography-based additive manufacturing of customized ceramics. Addit. Manuf., vol. 1, no. SEPTEMBER, pp. 110-118, 2014.

[7] Zhang, X., Jiang, X. N., and Sun, C.; Microstereolithography of polymeric and ceramic microstructures. Sensors Actuators, A Phys., vol. 77, no. 2, pp. 149-156, 1999.

[8] Stratasys - The 3D Printing Solutions Company - History. www.stratasys.com/corporate/aboutus.

[9] http://www.custompartnet.com

[10] Sun, Q., Rizvi, G. M., Bellehumeur, C. T., Gu, P.: Effect of processing conditions on the bonding quality of FDM polymer filaments. Rapid Prototyp. J., vol. 14, no. 2, pp. 72-80, 2008.

[11] Bikas, H., Stavropoulos, P. \& Chryssolouris, G. Int J Adv Manuf Technol (2016) 83: 389. https://doi.org/10.1007/s00170-015-7576-2

[12] Wong, K. V. Hernandez, A.: A Review of Additive Manufacturing. ISRN Mech. Eng., vol. 2012, pp. 1-10, 2012.

[13] Reprinted from Additive Manufacturing, Vol /8, Scott M.Thompson Linkan Bian Nima Shamsaei Aref Yadollahi, An overview of Direct Laser Deposition for additive manufacturing; Part I: Transport phenomena, modeling and diagnostics, Pages 36-62, Copyright (2015), with permission from Elsevier
[14] Budding, A., Vaneker, T. H. J.: New strategies for powder compaction in powder-based rapid prototyping techniques. Procedia CIRP, vol. 6, pp. 527-532, 2013.

[15] Manfredi, D., Calignano, F., Ambrosio, E. P., Krishnan, M., Canali, R., Biamino, S., Pavese, M., Fino, P., Badini, C., Atzeni, E., Luliano, L.: Direct Metal Laser Sintering: An additive manufacturing technology ready to produce lightweight structural parts for robotic applications. Metall. Ital., vol. 105, no. 10, pp. 15-24, 2013.

[16] Mellor, S.: An Implementation Framework for Additive Manufacturing. University of Exeter, March 2014.

[17] Gong, X., Anderson,T., Chou, K.: Review on powder-based electron beam additive manufacturing technology. Manuf. Rev., vol. 1, p. 2, 2014.

[18] Gibson I., Rosen D., Stucker B. (2015) Directed Energy Deposition Processes. In: Additive Manufacturing Technologies. Springer, New York, NY

[19] SAKLY, A.: Fabrication additive de pièces à base d'alliages métalliques complexes. Université de Lorraine - École Doctorale RP2E, 2013.

[20] Singh, R.: “ process capability study of a rapid polyjet printing for plastic components. J. Mech. Sci. Technol., 25: 1011, 2011.

[21] CustomPartNet.com - 3D Printing.: http://www.custompartnet.com/wu/3d-printing.

[22] Gibson I., Rosen D., Stucker B. (2015) Postprocessing. In: Additive Manufacturing Technologies. Springer, New York, NY

[23] Stratasys - Finishing Processes - Bead Blasting. :http://www.stratasys.com/solutions/finishingprocesses/bead-blasting.

[24] Sames, W. J., List, F. A., Pannala, S., Dehoff, R. R., Babu, S. S.: The metallurgy and processing science of metal additive manufacturing, Int. Mater. Rev., 2016.

[25] W.J. Sames, F. Medina, W.H. Peter, S.S. Babu, and R.R. Dehoff, Effect of Process Control and Powder Quality on Inconel 718 Produced Using Electron Beam Melting, John Wiley \& Sons Inc; 2014.

[26] Kruth, J. P., Mercelis, P., Froyen, L., Rombouts, M.: Binding mechanisms in selective laser sintering and selective laser melting. Rapid Prototyp. J., vol. 11, no. 1, pp. 26-36, 2005. "() Emerald Publishing Limited all rights reserved."

[27] Flynn, J. M., Shokrani, A., Newman, S.T., Dhokia, V.: Hybrid Additive and Subtractive Machine Tools - Research and Industrial Developments - 'to be published,"” Int. J. Mach. 
Tools Manuf., vol: 101 pp: 79-101, 2016.

[28] Able Electropolishing: Electropolishing - the final step in prototyping.

[29] Kruth, J. P., Mercelis, P., Froyen, L., Rombouts, M.: Binding mechanisms in selective laser sintering and selective laser melting. Rapid Prototyp. J., vol. 11, no. 1, pp. 26-36, 2005.

[30] Rivera, S., Panera, M., Miranda, D., Belzunce

[31] Reprinted from Applied Surface Science, Volume 255, D. Gu, Y. Shen, Processing conditions and microstructural features of porous $316 \mathrm{~L}$ stainless steel components by DMLS, 1880-1887, Copyright (2008), with permission from Elsevier.

[32] Zein, I., Hutmacher, D. W., Tan, K. C., Teoh, S. H. "Fused deposition modeling of novel scaffold architectures for tissue engineering applications," Biomaterials, vol. 23, no. 4, pp. 1169-1185, 2002.

[33] K. C. Ang, K. F. Leong, and C. K. Chua, "Investigation of the mechanical properties and porosity relationships in fused deposition modelling-fabricated porous structures," Rapid Prototyp. J., pp. 100-105, 2006.

[34] Liu, H., Sparks, T., Liou, F., Dietrich, D. M.: Residual Stress and Deformation Modelling for Metal Additive Manufacturing Processes. Proc. World Congr. Mech. Chem. Mater. Eng. (MCM 2015), 2015.

[35] Guo, N., Leu, M. C.: Additive manufacturing: Technology, applications and research needs. Front. Mech. Eng., vol. 8, no. 3, pp. 215-243, 2013.

[36] Wilkes J, Hagedorn Y C, Meiners W, Wissenbach K. Additive manufacturing of $\mathrm{ZrO} 2-\mathrm{A} 12 \mathrm{O} 3$ ceramic components by selective laser melting. Rapid Prototyping Journal, 2013, 19(1): 51-57

[37] Sood AK, Ohdar RK, Mahapatra SS (2010) Parametric appraisal of mechanical property of fused deposition modelling processed parts. Mater Des 31(1):287-295

[38] D. Manfredi, F. Calignano, E.P. Ambrosio, M. et al. "Direct Metal Laser Sintering: an additive manufacturing technology ready to produce lightweight structural parts for robotic applications". La Metallurgia Italiana, 105 (10), 2014, pages 15-25, ISSN 0026-0843

[39] Arcam, Press release - Arcam Expands Alcoa's 3D Printing Technology Portfolio, Delivers Arcam Q20plus.

[40] Arcam, Press release - LAI International Additive Manufacturing team has selected Arcam EBM technology.

http://www.arcamgroup.com/investorrelations/press-releases/2016/2/cisionarticle/
E6CAB666DF41B1B9/.

Hedges, M., and Marin, A. B.: 3D Aerosol Jet Printing - Adding Electronics Functionality to RP/RM. DDMC 2012 Conference, 14- 15.3.12, Berlin, 2012.

[42] LENS Blisk Repair Solution - Optomec

[43] Giffi, C. A., Gangula, B., Illinda, P.: 3D opportunity in the automotive industry: Additive manufacturing hits the road Contents. 2014.

[44] The Areion by Formula Group T: The World's First 3D Printed Race Car.:

http://www.materialise.com/en/cases/areion-byformula-group-t-worlds-first-3d-printed-race-car

[45] BMW: Manufacturing Jigs and Fixtures with FDM.:

http://www.stratasys.com/resources/\%20casestudies/automotive/bmw

[46] Mok, S. W., Nizak, R., Fu, S. C., Ho, K. K., Qin, L., Saris, D. B. F., Chan, K. M., Malda, J.: From the printer: Potential of three-dimensional printing for orthopaedic applications. J. Orthop. Transl., vol. 6, pp. 42-49, 2016.

[47] Stratasys, Applications de pointe - Produire des éléments IRM avec la FDM.

http://www.stratasys.com/fr/applications/applica tions-avancees/composants-mri.

[48] JUST ADD: Arcam - the innovative leader in additive manufacturing solutions for the production of orthopedic implants and aerospace components. 2016.

[49] Stratasys, Clinical Training Models http://www.stratasys.com/industries/medical/clin ical-training-models.

[50] Kang, H.-W., Lee, S. J., Ko, I. K., Kengla, C., Yoo, J. J., Atala, A.: A 3D bioprinting system to produce human-scale tissue constructs with structural integrity. Nat Biotech, vol. 34, no. 3, pp. 312-319, Mar. 2016.

[51] I. FiNNIE, T. ALTAN, D. A. DORNFELD, T. W. EAGAR, R. M. GERMAN, and M. G. JONES, Unit Manufacturing Process: Issues and Oppertunities in Research. National Academy of Sciences, 1995

[52] Gibson I., Rosen D., Stucker B. (2015) Introduction and Basic Principles. In: Additive Manufacturing Technologies. Springer, New York, NY

[53] Lieneke, T., Denzer, V., Adam, G. A. O., Zimmer, D.: Dimensional Tolerances for Additive Manufacturing: Experimental Investigation for Fused Deposition Modeling. Procedia CIRP, vol. 43, pp. 286-291, 2016.

[54] Lieneke, T., Adam, G. A. O., Leuders, S., Knoop,F., Josupeit, S., Delfs, P., Funke, N., Zimmer, D.: Systematical Determination of Tolerances for Additive Manufacturing by 
Measuring Linear Dimensions. 26th Annu. Int. Solid Free. Fabr. Symp., pp. 371-384, 2015.

[55] Bonnard, R.: Proposition de chaine numerique pour la fabrication additive. Ecole Centrale de Nantes, 2010.

[56] Pandey, P. M., Reddy, N. V., Dhande, S. G. :Slicing procedures in layered manufacturing: a review. Rapid Prototyp. J., vol. 9, no. 5, pp. 274-288, 2003.

[57] Wang, D. X., Guo, D. M., Jia, Z. Y., Leng, H. W.: Slicing of CAD models in color STL format. Comput. Ind., vol. 57, no. 1, pp. 3-10, 2006.

[58] Pei, E.: 4D printing - revolution or fad ?. Assem. Autom., vol. 34, no. 2, pp. 123-127, 2014.

[59] Stratasys, 4D Printing: Revolutionizing material form and control.

http://www.stratasys.com/industries/education/re search/4d-printing-project.

[60] R. Bogue, Assembly Automation, 29/3, Shape-memory materials: a review of technology and applications, 214-219 "๑) Emerald Publishing Limited all rights reserved."

[61] Self-Assembly LAB. http://www.selfassemblylab.net/research_project s.php.

[62] Ge, Q., Dunn, C. K., Qi, H. J., Dunn, M. L.: Active origami by $4 \mathrm{D}$ printing. Smart Mater. Struct., vol. 23, p. 15, 2014.

[63] Bogue, R.: Shape-memory materials: a review of technology and applications. Assem. Autom., pp. 214-219, 2009.

[64] Khoo, Z. X., Ee, J., Mei Teoh, J. E., Liu, Y., Chua, C. K., Yang, S., An, J.: 3D printing of smart materials: A review on recent progresses in 4D printing. Virtual Phys. Prototyp., pp. 103122,2015 
